\section{FORMAÇÃO DE JOGADORES DE FUTEBOL: PRINCÍPIOS E PRESSUPOSTOS PARA COMPOSIÇÃO DE UMA PROPOSTA PEDAGÓGICA}

\author{
TRAINING OF FOOTBALL PLAYERS: PRINCIPLES AND ASSUMPTIONS FOR A \\ PEDAGOGICAL PROPOSAL
}

\author{
FORMACIÓN DE JUGADORES DE FÚTBOL: PRINCIPIOS Y SUPUESTOS PARA \\ LA COMPOSICIÓN DE UNA PROPUESTA PEDAGÓGICA
}

\author{
Otávio Baggiotto Bettega*, Alcides José Scaglia**, Márcio Pereira Morato***, \\ Larissa Rafaela Galatti**
}

Palavras-chave

Futebol.

Educação Física

Formação

profissional. e treinamento.

Resumo: A constituição de uma proposta pedagógica para o ensino e treino do futebol deve considerar os diferentes fatores contextuais, priorizando demandas necessárias para 0 andamento do processo. 0 estudo configura-se como descritivo-propositivo e objetiva caracterizar princípios e pressupostos, apontando princípios balizadores e particulares para elaboração de uma proposta pedagógica para o processo formativo no futebol. Os princípios balizadores e particulares correspondem à teoria constituída objetivamente para atuação no jogo em diferentes etapas da formação. Os pressupostos referenciam as soluções frente aos problemas confrontados eventualmente. Portanto, a formação esportiva, além de somente fabricar respostas, deve capacitar os jogadores para os problemas inesperados.

Keywords:

Soccer.

Physical education

and training.

Professional training.

Palabras clave

Fútbol.

Educación Física y entrenamiento.

Formación profesional.
Abstract: The organization of a pedagogical proposal for teaching and coaching football should consider different contextual factors and focus on demands necessary for progress. This is a descriptive-purposeful study intended to characterize principles and assumptions, pointing guiding and specific principles for a proposed curriculum for the educational process in football. Those guiding and specific principles correspond to the theory objectively constituted to act in that game, in different stages of training. Assumptions are solutions to problems occasionally faced. Therefore, sports training should not only provide responses to its participants, but also enable players to solve unexpected problems.

Resumen: La estructuración de una propuesta pedagógica para la enseñanza y entrenamiento del fútbol debe considerar los diferentes factores contextuales, priorizando las demandas necesarias para el avance de este proceso. Esta investigación es descriptivo/propositiva y objetiva caracterizar principios y supuestos, señalando principios rectores y particulares para la elaboración de una propuesta pedagógica para el proceso formativo en el fútbol. Los principios rectores y particulares corresponden a la teoría constituida objetivamente para actuar en el juego en diferentes etapas de la formación. Los supuestos se refieren a las soluciones frente a los problemas eventuales. Por lo tanto, la formación deportiva debe, además de solamente fabricar respuestas, capacitar a los jugadores para enfrentar problemas inesperados.
*Universidade Federal de Santa Catarina. Florianópolis, SC, Brasil. E-mail: otavio.b.bettega @gmail.com

** Universidade Estadual de Campinas. Limeira, SP, Brasil.

E-mail: alcides.scaglia@gmail.com

***Universidade de São Paulo. Ribeirão Preto, SP, Brasil. E-mail:mpmorato@gmail.com

Recebido em: 22-07-2014

Aprovado em: 23-04-2015

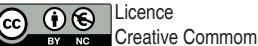




\section{INTRODUÇÃO}

O processo de formação dos jogadores deve ser abordado em longo prazo, considerando o desenvolvimento harmônico das capacidades intrínsecas dos atletas e as condições do ambiente de prática no qual estão inseridos. O futebol predispõe um ambiente competitivo, em que sua preparação orienta-se por alguns referenciais vinculados aos aspectos mais previsíveis do contexto, como a estrutura, as regras e características tático-técnicas. No entanto, esse ambiente é complexo e também passa pela imprevisibilidade, que tem incidência na incerteza e surpresa das ações e reações dos jogadores que visam solucionar os problemas de forma inteligente e eficaz (GARGANTA; CUNHA; SILVA, 2000).

Além disso, as situações reais do jogo vinculam-se a um determinado momento, sendo ele histórico, político, social, cultural, econômico, emocional, físico, cognitivo, estratégico, tático e técnico, designando diferentes significados aos que participam da ocasião. No caso do futebol, 0 esporte destaca-se pela sua universalidade (CASTELO, 1996), e seu apreço social o torna fonte de diferentes apreciações e investigações, tanto realizadas pelo senso comum como pela esfera acadêmica. Damo (2005) ressalta que a exposição e a acessibilidade do futebol abarcam uma diversidade de fatos empíricos, tornando-o fonte de diferentes significados e interesses. No caso desse estudo, o futebol volta-se para a formação de jogadores de elite em clubes de futebol, abordando conteúdos relevantes para atuação no jogo.

O mote dimensional que tange aos acontecimentos do jogo induz os jogadores a tomarem decisões que em muitas situações fogem à previsão antecipada (GARGANTA, 1994; 1997). A demonstração dos interesses que cada equipe objetiva no jogo é manifestada a partir da operacionalização do seu modelo de jogo. Considerando as equipes como sistemas dinâmicos em interação (conjuntos de jogadores que se relacionam), as manifestações estabelecidas como forma de exposição do modelo de jogo de uma equipe ligam-se estreitamente com os propósitos antagônicos da outra, sendo que essas relações tendem a gerar situações de ordem, desordem e organização (MORIN, 2002; SCAGLIA, 2011).

Um sistema consiste em uma entidade complexa, com elementos inter-relacionados garantindo-lhe uma identidade própria, com características de invariância no tempo (D'OTTAVIANO; BRESCIANI FILHO, 2004). Nesse sentido, a equipe de futebol é um sistema, uma vez que as ações dos jogadores são integradas numa determinada estrutura, segundo um determinado modelo, de acordo com certos princípios e regras (TEODORESCU, 1984).

Nesta compreensão as situações inerentes ao ambiente de jogo são mediadas a partir de processos sistêmicos de auto-organização e autotransformação, provocadas pelos diferentes elementos do sistema através de ações individuais e coletivas, em que as equipes se adaptam às condições advindas do confronto com o adversário, permeado por nuances de defesa e ataque. Os comportamentos de âmbito ofensivo refletem nas tomadas de ordem defensiva, sendo que o mesmo acontece inversamente. Assim, o reconhecimento das características defensivas e ofensivas nas esferas individuais e coletivas do sistema oposto surge como referencial importante para organização estratégica, bem como a antecipação de algumas ações nos momentos de jogo (SILVA et al., 2005).

O reconhecimento contextualizado norteia os propósitos da preparação e direciona as ações tomadas em ambiente competitivo. Nessa circunstância, o processo de ensino e treino no futebol, além de reconhecer o arcabouço de conhecimento e experiência dos indivíduos inseridos 
no grupo, deve identificar aspectos representativos do contexto de ação. Na organização de uma proposta voltada para o ensino do futebol, o reconhecimento da própria realidade e de inserção incide como fonte de retroalimentação, passando por situações mais e menos previsíveis. Para tanto, compreender a complexidade do processo de formação de jogadores passa pela compreensão fractal (no qual as partes mantêm características do todo) do próprio jogo, sendo estabelecidos processos de treino que transitam entre variabilidade e a permanência, legitimando o entendimento do processo (CUNHA E SILVA, 1995).

Essa transitabilidade entre as esferas mais e menos previsíveis interpõe o ambiente de jogo estabelecendo situações habituais e eventuais, assim, a interação entre os jogadores e com elementos de ordem estrutural, normativa e funcional se sustenta a partir de princípios (BAYER, 1994, CASTELO, 1996, TEOLDO et al., 2009; CASARIN et al., 2011, GARGANTA et al., 2013) que podem ser preestabelecidos antecipadamente. Por outro lado, é necessário acrescer ao processo os pressupostos, que correspondem às nuances de imprevisibilidade do jogo. Desse modo, o processo de ensino e treino no futebol deve considerar os diversos fatores que interferem na formação, compreendendo o processo formativo e suas respectivas etapas, bem como a atuação em momentos de maior e menor previsibilidade do jogo.

Assim, o estudo objetiva caracterizar princípios e pressupostos para o treino de jovens, apontando princípios balizadores e particulares para a elaboração de uma proposta pedagógica em longo prazo para formação de atletas de futebol.

\section{A COMPREENSÃO SISTÊMICA DO JOGO DE FUTEBOL E A FORMAÇÃO DE JOGADORES}

O jogo de futebol compreendido a partir da perspectiva sistêmica indica que o todo configura-se nas relações entre as partes, sinalizando que a mudança das partes para o todo também pode ser vista como uma mudança de objetos para relações (CAPRA, 2001). O futebol pode ser considerado um sistema dinâmico composto de muitas partes que interagem. As equipes, em uma visão macroscópica, podem caracterizar-se como subsistemas. A organização desses subsistemas acontece a partir das interações não lineares, que em nível microscópico se estabelece entre os jogadores, a bola, o árbitro e outros componentes do jogo (DAVIDS; ARAÚJO; SCHUTTLEWORTH, 2005).

O ambiente de jogo exige que os praticantes possuam uma adequada capacidade de decisão, concedida a partir de uma leitura de jogo apropriada (GARGANTA; PINTO, 1994). Para tanto, as aquisições sucessivas do jogador passam pela resolução de problemas, que podem surgir na compreensão, nas possibilidades de resolução e na automatização das respostas através da diversificação de situações (BAYER, 1994).

O jogo de futebol é circunstanciado por diferentes situações, que fundamentalmente caracterizam-se pelo seu caráter dualístico. Essas relações dispostas simultaneamente divergem dos seus interesses, configurando um confronto que se sustenta no equilíbrio e desequilíbrio. Essa disposição sistêmica, dada a manifestação dos jogadores, conduz a gestão de propriedades emergentes ao contexto, congregando-as a partir da interação entre indivíduo e ambiente (ARAÚJO, 2006). Ou seja, as condições de jogo são estabelecidas pelo confronto entre as equipes, que se estruturam a partir das ações individuais de cada jogador; tais ações são realizadas com base nos aspectos cognitivos e de execução motora, e circunstanciadas nas relações dispostas com o contexto de jogo, em paralelo à interação com atletas e equipe adversária. 
A atuação dos jogadores nas situações de jogo é representada pelas suas tomadas de decisão, que passam por momentos ocultos, referentes à percepção e escolha, e por momentos visíveis, correspondentes à execução (MAHLO, 1979). Essas situações são essencialmente de natureza tático-técnica e o caráter complexo e imprevisível atribui-se ao nível de interação entre indivíduo e ambiente a partir das intervenções perceptivas, de decisão e motoras (TAVARES; CASANOVA, 2013).

A concepção do jogo a partir de um sistema dinâmico intenciona a observação de padrões de estabilidade e instabilidade em circunstâncias específicas do jogo (JAMES et al., 2012). Essa visualização busca um recorte que passa pelas fases de defesa e ataque, que devem ser compreendidas como fractais (ou seja, ainda que analisadas em separado, tem-se claro que uma contém a outra). Essa fractalidade do jogo tem ocorrência na inter-relação das situações que se configuram a partir dos comportamentos e seus respectivos objetivos antagônicos; não sofrer gols e fazer o maior número possível destes (OLIVEIRA, 2004).

Considerando o exposto, o processo formativo na iniciação do futebol deve estabelecer uma diversidade de experiências, passando pelo reconhecimento de fatores externos ao jogo, bem como pelos aspectos internos, relacionados à atuação nas fases de defesa e ataque. $\mathrm{A}$ partir da iniciação plural é importante que se estabeleça a diversidade na formação ao longo das categorias de base, o que passa pela utilização de diferentes sistemas táticos, a partir de variados modelos de jogo, propiciando que 0 atleta tenha referências posicionais e funcionais diversificadas durante o seu percurso formativo. Sobretudo, a construção de um ambiente de aprendizagem em que os procedimentos e objetivos pedagógicos sejam alcançados converge para a ação de jogar carregada de intencionalidade e adaptabilidade (SCAGLIA et al., 2013).

Os comportamentos estabelecidos em nuances de defesa e ataque vinculam-se aos procedimentos didáticos constituídos no ensino e treino. Os modelos de exercícios podem se diferenciar quando no trato com a defesa e, logo, com o ataque. A diversificação das atividades para a estruturação defensiva e ofensiva busca facilitar o entendimento dos atletas, bem como coordenar as ações opositivas com intenção de recuperação, conservação e movimentação da bola para zonas que facilitem a finalização no alvo oponente (GRÉHAIGNE; GODBOUT, 1995).

A organização para atuação nas fases do jogo difere na sua exequibilidade. No âmbito defensivo as ações são realizadas sem a posse da bola e visam à sua retomada. No âmbito ofensivo, além da estruturação das movimentações de companheiros na oposição das ações adversárias, a equipe intenciona direcionar a bola para zonas que facilitem a aproximação à baliza do adversário. Nessa relevância, a construção didática do ensino deve facilitar a compreensão dos jovens atletas para atuação nesses diferentes momentos de jogo, considerando características temporais e espaciais da localização e movimentação da bola e dos jogadores (GRÉHAIGNE; WALLIAN; GODBOUT, 2005).

A formação de jogadores está vinculada às práticas diárias a partir de uma perspectiva sistêmica (visualização do todo e suas partes interligadas). Esse ambiente com uma cultura organizacional particular deve promover a discussão de valores, o comprometimento e a responsabilidade, bem como a capacidade de interagir de forma eficaz com treinadores, colegas, familiares e outros indivíduos pertencentes ao contexto (CÔTÉ; LIDOR; HOCKFORT, 2009, GALATTI, 2006, GALATTI et al., 2014, HENRIKSEN; STAMBULOVA; ROESSLER, 2010; MACHADO; GALATTI; PAES, 2012). 


\section{PRINCÍPIOS E PRESSUPOSTOS PARA ELABORAÇÃO DE UMA PROPOSTA PEDAGÓGICA NO FUTEBOL}

Dentre os diferentes fatores que interferem na atuação do jogador, a análise do comportamento tático-técnico deve considerar a sua relação com a estrutura formal do jogo, no qual interage constantemente com o espaço, a bola, os companheiros, os colegas e com as normas que regem o andamento do jogo (BAYER, 1994, GARGANTA, 1994, 2013, TAVARES, 1996, 2013). O sucesso e o insucesso na gestão do ambiente de jogo passam invariavelmente pela forma como as equipes são preparadas. Nesse propósito, a construção de uma proposta pedagógica para o ensino e treino do futebol deve considerar os diferentes desdobramentos do jogo, abordando as situações mais e menos previsíveis.

A constituição de uma proposta pedagógica para a formação de jogadores de futebol fundamenta-se a partir de princípios. Esses princípios vinculam-se à previsibilidade do jogo, reportando-se aos acontecimentos com maior ocorrência e que geralmente são treinados antecipadamente. Os princípios orientam o comportamento dos jogadores nos momentos defensivos e ofensivos, estabelecendo normas de ação objetivamente constituídas a partir da aprendizagem de uma teoria mais específica do jogo. Eles se caracterizam como o ponto de partida e fundamento de um processo qualquer. Aquilo que parte de um processo de conhecimento (ABBAGNANO, 2007).

As intenções defensivas e ofensivas estabelecidas no contexto de jogo são processadas pelos jogadores. Esses jogadores são detentores de funções específicas (goleiro, lateral, zagueiro, meio-campo, atacante) com vista à resolução eficaz de problemas momentâneos do jogo, em conformidade com princípios balizadores e princípios mais particulares. Esses princípios estabelecem um quadro referencial que possibilita a resolução de problemas já explorados anteriormente e a criação de novos problemas que levam o jogador a obter conhecimentos subjetivamente novos (CASTELO, 1996).

0 confronto com novos problemas em meio ao jogo atrela-se à variabilidade do contexto. Esses momentos menos previsíveis estabelecem uma autoadaptação e os princípios preestabelecidos instituem pressupostos que norteiam essa variância do jogo e aumentam 0 nível de complexidade sistêmica, reportando-se à criação de outros princípios e gerando uma nova organização. Esses novos padrões de organização podem surgir tanto nas interações entre o jogo e o meio como a partir das interações dos elementos internos do jogo (CAPRA, 2001, MORIN, 2002).

Os jogos esportivos coletivos, e, nesse caso, ofutebol, apresentam princípios fundamentais e operacionais vinculados à funcionalidade do jogo (BAYER, 1994). Nessa conformidade, o Quadro 1 apresenta esses princípios como balizadores.

Quadro 1 - Princípios Balizadores

\begin{tabular}{|l|l|l|}
\hline \multicolumn{3}{|c|}{ Princípios Fundamentais } \\
\hline Recusar a inferioridade numérica & Evitar a igualdade numérica & Criar superioridade numérica \\
\hline \multicolumn{1}{|c|}{ Fases } & \multicolumn{1}{|c|}{ Defesa } & \multicolumn{1}{c|}{ Ataque } \\
\hline Princípios Operacionais & $\begin{array}{l}\text { Recuperar a posse da bola } \\
\text { Impedir a progressão ao alvo } \\
\text { Proteger o alvo }\end{array}$ & $\begin{array}{l}\text { Manter a posse de bola } \\
\text { Progredir ao alvo adversário } \\
\text { Atacar o alvo adversário }\end{array}$ \\
\hline
\end{tabular}


A partir dos princípios balizadores, comuns ao conjunto de Jogos Esportivos Coletivos, estruturamos os princípios particulares (Quadro 2) sustentados a partir da experiência prática em concomitância com estudos sobre a classificação de princípios de jogo específicos do futebol (CASARIN et al., 2011, CASTELO, 1996, GARGANTA; PINTO, 1994, GARGANTA et al., 2013, PARREIRA, 2005, TEOLDO et al., 2009). Sustentam também o quadro estudos de referência nas etapas de formação esportiva (BALYI, 2001, BOMPA, 2002, CÔTÉ, 1999, GRECO; BENDA, 1998, SAMELA; DURAND-BUSH; DURAND, 1994).

Quadro 2 - Princípios Particulares

\begin{tabular}{|c|c|c|}
\hline ETAPAS / FASES & DEFESA & ATAQUE \\
\hline $\begin{array}{l}\text { DIVERSIFICAÇÃO } \\
\text { (5 anos - } 8 \text { anos) }\end{array}$ & \multicolumn{2}{|c|}{$\begin{array}{l}\text { Jogos variados e diversificados com passagens pelas funções ofensivas e } \\
\text { defensivas de maneira livre. }\end{array}$} \\
\hline $\begin{array}{l}\text { INICIAÇÃO } \\
\text { (9 anos - } 11 \text { anos) }\end{array}$ & $\begin{array}{l}\text { - Apresentação de referenciais com base } \\
\text { no oponente e com pouca delimitação } \\
\text { espacial.- Ênfase na defesa individual } \\
\text { setorizada (maior preocupação com o } \\
\text { adversário do que com o setor).- Maior } \\
\text { ênfase na ocupação de espaços no } \\
\text { âmbito da profundidade do campo } \\
\text { (muita referência ao alvo).- Ênfase na } \\
\text { marcação (aproximação e abordagem, } \\
\text { 1x1), na dobra de marcação ( } 2 \times 1 \text { ) e no } \\
\text { fechamento de linhas de passe (1x2, } \\
\text { 2x3). } \\
\text { - Desenvolvimento de noções de } \\
\text { flutuação do bloco, com maior referência } \\
\text { em âmbito de largura do campo.- Ênfase } \\
\text { no posicionamento atrás e à frente } \\
\text { da linha da bola, principalmente nos } \\
\text { momentos de recomeço do jogo (tiro de } \\
\text { meta, falta, lateral, escanteio).- Enfatizar } \\
\text { as ações defensivas com base nas zonas } \\
\text { de atuação, que podem ser de "conforto" } \\
\text { ou de "risco". }\end{array}$ & $\begin{array}{l}\text { - Organização do ataque enfatizando } \\
\text { um jogo mais direto (através de passes } \\
\text { longos), mas apresentando opções para } \\
\text { a constituição de um jogo mais indireto } \\
\text { (através de passes curtos).- Procurar manter } \\
\text { um equilíbrio setorial na distribuição dos } \\
\text { jogadores, pois as movimentações centram- } \\
\text { se muito na trajetória da bola.- Ênfase na } \\
\text { exposição de referenciais que facilitem } \\
\text { a organização ofensiva no momento de } \\
\text { recomeço do jogo.- Organização ofensiva } \\
\text { com ênfase em bolas lançadas para as } \\
\text { extremidades da largura e profundidade do } \\
\text { campo, pois o centro de jogo geralmente } \\
\text { é mais congestionado.- Enfatizar a busca } \\
\text { por situações de superioridade e igualdade } \\
\text { numérica principalmente próximas ao alvo } \\
\text { (1x1, 2x2, 1x0, 2x1, 3x2) para facilitar as } \\
\text { finalizações. } \\
\text { - Enfatizar a alternância posicional em } \\
\text { situações de bola parada para facilitar a } \\
\text { compreensão. }\end{array}$ \\
\hline $\begin{array}{l}\text { TRANSIÇÃO } \\
\text { (12 anos - } 14 \text { anos) }\end{array}$ & $\begin{array}{l}\text { - Defesa individual setorizada com maior } \\
\text { delimitação espacial.- Desenvolvimento } \\
\text { de uma maior compactação em largura } \\
\text { e profundidade.- Ênfase nas ações } \\
\text { com referenciais mais setoriais do que } \\
\text { individuais.- Regra do impedimento: } \\
\text { apresentação de ações mais } \\
\text { individualizadas.- Desenvolvimento } \\
\text { da pressão ao portador da bola, com } \\
\text { indução a zonas de maior dificuldade } \\
\text { para o atacante e fechamento de linhas } \\
\text { de passe.- Apresentação de noções de } \\
\text { retorno para trás da linha da bola em } \\
\text { momentos de quebra de marcação.- } \\
\text { Bloqueio de corredores, principalmente } \\
\text { o central.- Desenvolvimentos de ações } \\
\text { iniciais com o goleiro atuando como } \\
\text { cobertura. }\end{array}$ & $\begin{array}{l}\text { - Sobreposição de um jogo indireto (através } \\
\text { de passes curtos) na relação com um } \\
\text { jogo direto (através de passes longos), } \\
\text { principalmente no setor ofensivo.- Devido } \\
\text { a uma maior compactação, enfatizar } \\
\text { movimentos de concentração e expansão } \\
\text { do bloco, para assim facilitar a troca de } \\
\text { passes.- Utilização do goleiro como linha } \\
\text { de passe para eventuais dificuldades nas } \\
\text { saídas do campo defensivo.- Enfatizar } \\
\text { movimentos com alternância simples de } \\
\text { posições em meio à construção de ações } \\
\text { ofensivas.- Desenvolver movimentos com e } \\
\text { sem bola criando situações de superioridade } \\
\text { numérica e para desequilibrar partes dos } \\
\text { setores de defesa adversário.- Enfatizar a } \\
\text { criação de espaços nos corredores laterais } \\
\text { do campo ofensivo através da circulação } \\
\text { da bola, para assim propiciar situações de } \\
\text { finalização. }\end{array}$ \\
\hline
\end{tabular}




\begin{tabular}{|c|c|c|}
\hline $\begin{array}{l}\text { ESPECIALIZAÇÃO } \\
\text { (15 anos - } 17 \text { anos) }\end{array}$ & $\begin{array}{l}\text { - Defesa individual setorizada com } \\
\text { desenvolvimento de referências } \\
\text { zonais.- Ênfase na constituição de linhas } \\
\text { defensivas, configurando o todo como } \\
\text { um bloco compacto e coeso.- Criação } \\
\text { de zonas de pressão.- Apresentação de } \\
\text { movimentações que induzam a bola para } \\
\text { zonas de pressão.- Estratégias coletivas } \\
\text { para reequilíbrio após quebras de linhas } \\
\text { defensivas.- Desenvolvimento de ações } \\
\text { de "pressing" na busca da retomada da } \\
\text { posse de bola.- Goleiro participando } \\
\text { ativamente da fase defensiva.- } \\
\text { Desenvolvimento da comunicação } \\
\text { motora para determinar o tempo de } \\
\text { abordagem da defesa. }\end{array}$ & $\begin{array}{l}\text { - Estruturação de um jogo mais indireto } \\
\text { (através de passes curtos), enfatizando a } \\
\text { aproximação e abertura de linhas de passe. } \\
\text { - Aproximação e criação de linhas de passe } \\
\text { em diferentes setores do campo, para } \\
\text { assim facilitar a manutenção da posse de } \\
\text { bola.- Utilização do goleiro como linha de } \\
\text { passe facilitadora da manutenção da posse } \\
\text { de bola. } \\
\text { - Criação de movimentos mais frequentes } \\
\text { com alternância de posições em diferentes } \\
\text { zonas do campo. } \\
\text { - Desenvolver movimentações para } \\
\text { quebra de linhas defensivas do adversário } \\
\text { e consequentemente abertura de } \\
\text { espaços para infiltrações.- Realização } \\
\text { de movimentações no setor ofensivo } \\
\text { com abertura de espaços em corredores } \\
\text { laterais e centrais para, assim, facilitar as } \\
\text { finalizações. }\end{array}$ \\
\hline $\begin{array}{l}\text { CONSOLIDAÇÃO } \\
\text { ( } \geq 17 \text { anos) }\end{array}$ & \multicolumn{2}{|c|}{ Direcionado aos interesses inerentes ao modelo de jogo exposto pelo treinador } \\
\hline
\end{tabular}

Fonte: Côté (1999); Garganta, Pinto (1994)

Nossa proposta indica considerar as etapas de diversificação e consolidação, mas não apresenta princípios particulares defensivos e ofensivos para ela. Isso porque na etapa de diversificação não se indica atribuir priorização de nenhuma das fases do jogo, mas sim proporcionar diversidade de experiências através de jogo, atuando nas fases de defesa e ataque. Na etapa de consolidação, por sua vez, os princípios particulares devem estar associados a um modelo de jogo específico, o que é construído sob a liderança do treinador, em uma etapa em que a formação já se estabeleceu e se considera a forte influência da busca por resultados competitivos (RATHWELL; BLOOM; LOUGHEAD, 2014).

Uma vez apresentados os princípios norteadores de uma proposta pedagógica para formação de atletas de futebol, tendo em vista a sistematicidade da modalidade é necessário respeitar seus componentes menos previsíveis, aqui tratados por pressupostos. Os pressupostos de jogo caracterizam-se pela subjetividade, repousando seus acontecimentos nos momentos mais imprevisíveis e que geralmente não obtiveram simulações preestabelecidas (ABBAGNANO, 2007). Nesse propósito, a subjetividade vinculada aos padrões estabelecidos no trato com fenômenos permite uma realidade com ocorrências mais espontâneas e naturais (CUNHA E SILVA, 1995).

As situações do jogo em muitas ocasiões instituem-se de maneira diferenciada aos acontecimentos do treino. Essa variabilidade do contexto muitas vezes não pode ser resolvida a partir dos princípios constituídos no treinamento (ARAÚJO, 2009). O jogador deve se autoadaptar em função das emergências do jogo e buscar a resolução dos problemas a partir dos pressupostos. Por exemplo, o ato de passar a bola em meio ao jogo não se restringe à ação motora ou ao princípio de conservação da bola entre companheiros de equipe. Logo, a alternância que essa ação causa na ocorrência do jogo interpõe o plano inicial e a resolução do problema configura-se de um princípio (plano instituído para a conservação da bola através do passe) para um pressuposto (ação do passe tomada de forma diferenciada devido às mudanças do contexto). 
Considerando os pressupostos de jogo no ensino e treino do futebol, o seu desenvolvimento geralmente atrela-se a situações não específicas, orientando-se pela interação pessoal com os desdobramentos contextuais (BRONFENBRENNER, 1977, KREBS et al., 2011). Nesse sentido, os pressupostos vinculam-se em grande parte à autoadaptação do indivíduo na realização de ações em momentos menos previsíveis do jogo, que geralmente não foram simulados anteriormente.

O jogo é permeado pelo visível e o oculto, pela defesa e ataque, pelo tático e técnico. Essa transição entre polos interpõe a teoria inicial que é constituída a partir de princípios de jogo objetivados previamente. O jogo vai além do treino, do controlável, do previsível, torna-se dependente também da variabilidade e imprevisibilidade das situações, assim induzindo o jogador à descoberta de pressupostos para a tentativa de resolução dos problemas diferentes da tarefa (ARAÚJO, 2009).

\section{CONSIDERAÇÕES FINAIS}

A construção de uma proposta pedagógica para orientação do processo de ensino e treino no futebol transcende os conteúdos específicos da modalidade. Essa disposição na perspectiva sistêmica interpõe níveis sistêmicos, considerando fatores de ordem social, cultural, econômica, histórica e política. Dentre os focos de abrangência da formação esportiva, os aspectos físicos, psicológicos e tático-técnicos norteiam o processo.

O direcionamento das prioridades do processo configura-se a partir das necessidades e interesses dos indivíduos em confluência com as condições contextuais estabelecidas. Nessa relevância, o processo de ensino e treino no futebol direcionado para o contexto de estudo sinaliza que os aspectos tático-técnicos devem ser a prioridade do processo, mas não a totalidade. Nessa conjuntura, os conteúdos constituídos para uma proposta pedagógica de formação no futebol devem interagir com meios mais e menos específicos, bem como sustentando a atuação a partir dos princípios (emergentes dos conhecimentos previamente estabelecidos) e dos pressupostos (emergentes da adaptação a partir das mudanças contextuais).

\section{REFERÊNCIAS}

ABBAGNANO, Nicola. Dicionário de filosofia. São Paulo: Martins Fontes, 2007.

ARAÚJO, Duarte. Tomada de decisão no desporto. Lisboa: FMH Edições, 2006.

ARAÚJO, Duarte. O desenvolvimento da competência táctica no desporto: o papel dos constrangimentos no comportamento decisional. Motriz, Rio Claro, v. 15, n. 3, p. 537-540, 2009.

BALYI, Istvan. Sport system building and long-term athlete development in British

Columbia. British Columbia: SportsMed, 2001.

BAYER, Claude. 0 ensino dos desportos colectivos. Lisboa: Dinalivro, 1994.

BOMPA, Tudor. Treinamento total para jovens campeões. Barueri: Manole, 2002.

BRONFENBRENNER, Urie. Toward an experimental ecology of human development. American

Psychologist, Washington, v. 32, n. 7, p. 513-531 1977. 
CAPRA, Fritjof. A teia da vida. 6. ed. São Paulo: Cultrix, 2001.

CASARIN, Rodrigo Vicenzi et al. Modelo de jogo e processo de ensino no futebol: princípios globais e específicos. Movimento, Porto Alegre, v. 17, n. 3, p. 133-152, 2011.

CASTELO, Jorge. Futebol: a organização do jogo. Edição do Autor, 1996.

CÔTÉ, Jean. The influence of the family in the development of talent in sports. The Sport Psychologist, Champaign, v. 13, n. 4, p. 395-417, 1999.

CÓTÊ, Jean; LIDOR, Ronnie; HOCKFORT, Dieter. To sample or to specialize? Seven postulates about youth sport activities that lead to continued participation and elite performance. International Journal of Sport and Exercise Psychology, London, v. 7, n. 1, p. 7-17, 2009.

CUNHA E SILVA, Paulo. O lugar do corpo. Elementos para uma cartografia fractal. 1995. $313 \mathrm{f}$. Tese (Doutorado em Ciência do Desporto) - Faculdade de Ciências do Desporto e da Educação Física, Universidade do Porto, Porto, 1995.

DAMO, Arlei. Do dom à profissão: uma etnografia do futebol de espetáculo a partir da formação de jogadores no Brasil e na França. 2005. 435 f. Tese (Doutorado em Antropologia Social) - Instituto de Filosofia e Ciências Humanas, Universidade Federal do Rio Grande do Sul, Porto Alegre, 2005.

DAVIDS, Keith; ARAÚJO, Duarte; SHUTTLERWORTH, Rick. Applications of dynamical systems theory to football. In: REILLY, Thomas; CABRI, Jan; ARAÚJJO, Duarte. (Ed.). Science and football V: the Proceedings of the Fifth World Congress on Science and football. London: Rowtledge, 2005. p. 557-569.

D'OTTAVIANO, Itala Maria Loffredo; BRESCIANI FILHO, Ettore. Auto-organizacão e criação. MultiCiência, Campinas, n. 3, p. 1-23, out. 2004, Disponível em: <http://www.multiciencia. unicamp.br/rede 2 3.htm>. Acesso em: 5 abr. 2015.

GALATTI, Larissa Rafaela. Pedagogia do Esporte: o livro didático como mediador no processo de ensino e aprendizagem dos jogos esportivos coletivos. 2006. 71f. Dissertação (Mestrado) Faculdade de Educação Física, Universidade Estadual de Campinas, Campinas, 2006.

GALATTI, Larissa Rafaela et al. Pedagogia do Esporte: tensão na ciência e o ensino dos Jogos Esportivos Coletivos. Revista da Educação Física/UEM, Maringá, v. 25, n. 1, p. 153-162, 2014.

GARGANTA, Júlio. Modelação táctica do jogo de futebol. Estudo da organização da fase ofensiva em equipes de alto rendimento. 1997. 159f. Tese (Doutorado em Ciências do Desporto) - Faculdade de Ciências do Desporto e da Educação Física, Universidade do Porto, Porto, 1997.

GARGANTA, Júlio. Para uma teoria dos jogos desportivos colectivos. In: GRAÇA, Amândio; OLIVEIRA, José. (Org.). 0 ensino dos jogos desportivos. 2. ed. Porto: Universidade do Porto, 1994. p.11-25.

GARGANTA, Júlio. A propósito do desenvolvimento, da identificação e da atualização do talento para treinar e jogar futebol. In: NASCIMENTO, Juarez Vieira; RAMOS, Valmor; TAVARES, Fernando. (Org.). Jogos desportivos: formação e investigação. Florianópolis: Tribo da llha, 2013.

GARGANTA, Júlio et al. Fundamentos e práticas para o ensino e treino do futebol. In: TAVARES, Fernando. (Org.). Jogos desportivos coletivos: ensinar a jogar. Porto: Editora FADEUP, 2013. 
GARGANTA, Júlio; CUNHA e SILVA, Paulo. O jogo de futebol: entre o caos e a regra. Revista Horizonte, Porto, v. 16, n. 91, p. 5-8, 2000.

GARGANTA, Júlio; PINTO, Jorge. O ensino do futebol. In: GRAÇA, Amândio; OLIVEIRA, José. 0 ensino dos jogos desportivos. Porto: Universidade do Porto, 1994.

GRECO, Pablo Juan; BENDA, Rodolfo. (Org.). Iniciação esportiva universal. Belo Horizonte: Editora UFMG, 1998.

GRÉHAIGNE, Jean; GODBOUT, Paul. Tactical knowledge in team sports from a constructivist and cognitivist perspective. Quest, Champaign, v. 47, p. 490-505, 1995.

GRÉHAIGNE, Jean; WALLIAN, Nathalie; GODBOUT, Paul. Tactical-decision learning model and students practices. Physical Education and Sport Pedagogy, London, v. 10, n. 3, p. 255-269, 2005.

HENRIKSEN, Kristoffer; STAMBULOVA, Natalia; ROESSLER, Kirsten Kaya. Holistic approach to athletic talent development environments: a successful sailing milieu. Psychology of Sport and Exercise, London, v. 11, n. 3, p. 212-222, 2010.

JAMES, Nick et al. Analysing soccer using perturbation attempts. Journal of Human Sport \& Exercise, Alicante, v. 7, n. 2, p. 413-420, 2012.

KREBS, Ruy Jornada et al. Disposição de adolescente para a prática de esportes: um estudo orientado pela Teoria Bioecológica de Bronfenbrenner. Motriz, Rio Claro, v. 17, n. 1, p. 195-201, 2011.

MACHADO, Gisele Viola; GALATTI, Larissa Rafaela; PAES, Roberto Rodrigues. Seleção de conteúdos e procedimentos pedagógicos para o ensino do esporte em projetos sociais: reflexões a partir dos jogos esportivos coletivos. Motrivivência, Florianópolis, . 39, p. 164-176, 2012.

MAHLO, Friederich. 0 acto táctico no jogo. Lisboa: Compendium, 1979.

MORIN, Edgar. 0 método I: a natureza da natureza. Porto Alegre: Sulina, 2002.

OLIVEIRA, José Guilherme. Conhecimento específico em futebol. Contributos para definição de uma matriz dinâmica do processo de ensino-aprendizagem/treino do jogo. 2004. $99 f$ Dissertação (Mestrado em Ciências do Desporto) - Faculdade de Ciências do Desporto e da Educação Física, Universidade do Porto, Porto, 2004.

PARREIRA, Carlos Alberto. Evolução tática e estratégias de jogo. Brasília: Ed. EBF, 2005.

RATHWELL, Scott; BLOOM, Gordon; LOUGHEAD, Todd. Head coaches' perceptions on the roles, selection, and development of the assistant coach. International Sport Coaching Journal, Champaign, v. 1, n. 1, p. 5-16, 2014.

SAMELA, John; DURAND-BUSH, Nathalie; DURAND, Marc. La détection des talents ou le développement de l'expertise en sport. Persée, v. 47, n. 2, p. 233-245, 1994.

SCAGLIA, Alcides José. 0 futebol e as brincadeiras de bola: a família dos jogos de bola com os pés. São Paulo: Phorte, 2011.

SCAGLIA, Alcides José et al. O ensino dos jogos esportivos coletivos: as competências essenciais e a lógica do jogo em meio ao processo organizacional sistêmico. Movimento, Porto Alegre, v. 19, n. 4, p. 227-249, 2013. 
SILVA, António et al. Patrones de juego en el fútbol de alto rendimiento. Análisis secuencial del proceso ofensivo en el campeonato del mundo Corea-Japón 2002. Cultura, Ciencia y Deporte, Murcia, v. 1, n. 2, p. 65-72, 2005.

TAVARES, Fernando. Bases teóricas da componente táctica nos jogos desportivos colectivos. In: OLIVEIRA, José; TAVARES, Fernando. Estratégia e táctica nos jogos desportivos colectivos. Porto: Editora da Universidade do Porto, 1996.

TAVARES, Fernando. Jogos desportivos coletivos: a ação tática está na mente do jogador ou no contexto da situação? In: NASCIMENTO, Juarez Vieira; RAMOS, Valmor; TAVARES, Fernando. (Org.). Jogos desportivos: formação e investigação. Florianópolis: Tribo da llha, 2013.

TAVARES, Fernando; CASANOVA, Felipe. A atividade decisional do jogador nos jogos desportivos coletivos. In: TAVARES, Fernando. (Ed.). Jogos desportivos coletivos: ensinar a jogar. Porto: Editora da Universidade do Porto, 2013.

TEODORESCU, Leon. Problemas de teoria e metodologia nos jogos desportivos. Lisboa: Livros Horizonte, 1984.

TEOLDO, Israel et al. Princípios táticos do jogo de futebol: conceitos e aplicação. Motriz, Rio Claro, v. 15, n. 3, p. 657-668, 2009. 